\title{
A Comparative Study on the Usage of RON68 and Naphtha in an HCCI Engine
}

\author{
Emre Y1lmaz ${ }^{1}$ \\ 0000-0002-5653-2079 \\ ${ }^{1}$ Sakarya University of Applied Sciences, Department of Motor Vehicles and Transportation Technologies, 54580, Sakarya, TURKEY
}

\begin{abstract}
The depletion of fossil fuels as a result of excessive useage and increased environmental pollution brought up the research of environmentally conscious and renewable alternative fuels.The alternative fuel to be considered for internal combustion engines should not decrease the performance of the engine too much and positively affect the exhaust emissions. It is also important that this fuel should provide some specifications such as easy producibility, low cost, availability and usability in internal combustion engine without modification. Low temperature combustion modes are promising technologies providing nearly zero $\mathrm{NO}_{\mathrm{x}}$ and soot emissions and currently a lot of researcher has focused on this technology. In this experimental study naphthaand RON68 was tested in an HCCI engine. In order to examine and understand the effects of the naphtha on HCCI mode a comparison study was also conducted by using RON68.Maximum imep was computed as 3.23 and 3.32 bar with RON68 and naphtha respectively at $\lambda=1.7 . \mathrm{SOC}$ was determined $5.4{ }^{\circ} \mathrm{CA}$ and $5.76^{\circ} \mathrm{CA} \mathrm{ATDC}$ with naphtha and RON68 at $\lambda=2$.CA50 is far away from TDC fact that net work decreases. Maximum ITE was calculated as $45.42 \%$ and $46.07 \%$ at $\lambda=2$ with RON68 and naphtha respectively.
\end{abstract}

Keywords: Combustion; HCCI; Naphtha; RON68;
* Corresponding author

Emre Y1lmaz

emreylmz@subu.edu.tr

Adress:Department of Automotive Vehicles and Transportation Technologies, ArifiyeVocational High School, Sakarya University of Applied Sciences, Sakarya, Turkey

Tel:+90(264)6160054

Researh Article

Manuscript

Received $\quad 17.04 .2020$

Revised $\quad 09.05 .2020$

Accepted $\quad 23.05 .2020$

Doi: 10.30939/ijastech..721882

\section{Introduction}

The global economy and modern societies need reliable transportation systems to continue their development and growth. In terms of physical possibilities, modern civilization could not reach the current living standards without the use of automotive devices. The main power source of automotive vehicles such as planes, ships, agricultural machinery, construction equipment, construction equipment, generators etc. are internal combustion engines [1]. The vast majority of internal combustion engines currently used in automotive vehicles are reciprocating engines operating by combustion of fossil fuels of petroleum origin. Due to their superior performance and controllability, durability and other unviable alternatives, internal combustion engines have been the primary source of power since the last century.
However, in order to ensure sustainable development, it is necessary to obtain the energy used in transportation from sources with low carbon footprint. In addition, due to the rapidly increasing world population and mechanism, the demand for fossil fuels and the number of automotive vehicles have increased sharply in recent years [2,3]. Carbon dioxide, sulfur dioxide, nitrous oxide, dust and soot released into the atmosphere when fossil fuels are burned, while carbon dioxide and similar greenhouse gases cause global climate change and threaten life in all countries of the world [4]. Researchers are trying to reduce the use of fossil fuels by developing new technologies in alternative combustion modes [5-7], vehicle technologies [8-11], alternative fuels and additives [12-18]. 
As an low temperature combustion mode, the main advantages of the homogeneous charge compression ignition ( $\mathrm{HCCI}$ ) combustion mode low $\mathrm{NO}_{\mathrm{x}}$ and smoke emissions simultaneously without any loss in the thermal efficiency for the same compression ratio [19-25]. Onishi and Noguchi conducted the first studies related to the HCCI combustion in 1979 [26,27]. The charge mass is prepared homogeneously as in spark-ignition engines and as likely compression ignition engines the mixture auto-ignited via compression in the HCCI combustion concept. Therefore, combustion occurs simultaneously in whole range in the cylinder [28-30]. By considering the mixture preparation and start of the combustion, HCCI engines are explained as an engine in a range of spark ignition and compression ignition engines. HCCI engines generally provide nearly zero smoke emissions due to the homogeneously prepared lean mixture. The lean mixture preparation is also help to reduce $\mathrm{NO}_{\mathrm{x}}$ emissions because the peak in-cylinder gas temperatures decreases when the engine operated with leaner mixtures [31-33]. Because of these advantages, HCCI combustion mode take attention over last few decades and researchers have performed a lot of studies about HCCI combustion. In most of these experimental researches reference fuels are tested in HCCI engines as well as the using alternative fuels such as natural gas, liquid petroleum gas, biodiesel and alcohol [34-38].

Naphtha is produced from refining the crude oil. It is an intermediate hydrocarbon and might be useful for internal combustion engines as well [39]. However, there are very limited studies about naphtha usage on internal combustion engines in the literature. Wang et al. [32] achieved HCCI combustion in a gasoline direct injection engine by using naphtha and gasoline. Gasoline and naphtha were injected into the cylinder via stepwise injection strategy at a pressure of $80 \mathrm{MPa}$. Multiple injection pulses used to optimize emissions and efficiency. Stepwise injection of gasoline and naphtha were compared the test results of diesel fuel in compression ignition engine. The operation range of the HCCI engine extended with the usage of naphtha fuel by stepwise injection strategy. In case of using gasoline, excessive misfiring was observed. The maximum indicated thermal efficiency was $47 \%$ in use of naphtha. Indicated specific fuel consumption was recorded below $200 \mathrm{~g} / \mathrm{kWh}$ at higher engine loads. Another naphtha study was conducted by Vallinayagam et al. [31]. They investigated combustion and emission variations of US test diesel, EU test diesel, RON60 and naphtha in different combustion modes. The test fuels were prepared by keeping constant cetane number of 36 for all test fuels. Experiments were carried out in HCCI, partially premixed charged ignition (PPC) and CI combustion modes with an optical test engine. It was found that a higher inlet temperature is required to burn diesel test fuels in PPC combustion mode. The maximum in-cylinder pressure was obtained with RON60 in HCCI combustion mode. In CI mode, the maximum cylinder pressure was occurred in use of naphtha.

In this experimental study naphtha and RON68 was tested in an HCCI engine. In this study, RON68 fuel was used because the octane number of naphtha fuel was 68.In order to examine and understand the effects of the naphtha on HCCI mode a comparison study was also conducted by using RON68 (68\% isooctane and 32\% nheptane by vol.). To make a proper comparison on the test results, octane numbers of the both fuels were set up same. Experiments were carried out in a single cylinder port fuel injection gasoline engine. In-cylinder pressure traces, heat release rate curves, combustion and emission characteristics were examined in detail.

\section{Material and Method}

In the experiments, single cylinder, four stroke and port injection system HCCI test engine was used. The test engine was the Ricardo Hydra model. Test engine was transformed into the HCCI engine from the spark ignition engine. List of the specifications of test engine is shown in Table 1. Further, the HCCI test bench is shown in Figure 1.

Table 1. The test engine specifications

\begin{tabular}{ll}
\hline Test Engine & Ricardo Hydra \\
\hline Cylinder number & 1 \\
Max. engine speed [rpm] & 5400 \\
Compression ratio & $13 / 1$ \\
Valve lift [mm] & Exhaust lift 3.5, \\
& Intake lift 5.5 \\
Stroke x bore [mm] & $88.90 \times 80.26$ \\
Max. power output $[\mathrm{kW}]$ & 15 \\
\hline
\end{tabular}

The air fuel mixture was prepared in the intake manifold by using the port injection fuel system. The amount of fuel to be injected is set via the control unit. While the fuel tank was placed on the precision balance, fuel consumption was determined by the time of 120 seconds. The fuel consumption was formulated with the fuel injection characteristic obtained. 


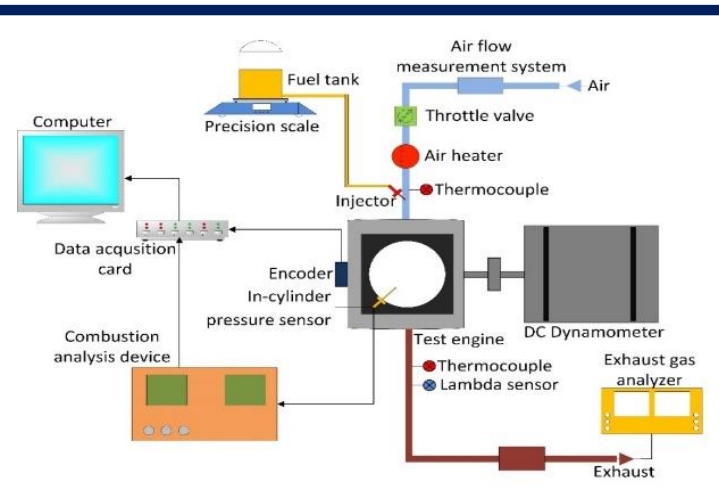

Fig. 1. Schematic view of HCCI test bench

The test motor was connected to an electric type dynamometer capable of absorbing $30 \mathrm{~kW}$ of power. The brand of the dynamometer was McClure. The intake air heater device was located on the intake manifold, just before the fuel injection system. The inlet air temperature was measured by a $\mathrm{K}$ type thermocouple where it placed between the air heater and the injection system. Air inlet temperature was set on the control panel. In the experiments, the original air heater system was used. The Kistler6121 model piezoelectric pressure sensor was used for determine the in-cylinder pressure. The crank position versus the in-cylinder pressure was determined using an encoder with a precision of $0.36^{\circ} \mathrm{CA}$. Properties of encoder are shown in Table 2.

Table 2. Properties of encoder

\begin{tabular}{ll}
\hline Encoder & Opkon \\
\hline Supply voltage & $5 \mathrm{~V}$ \\
Operating temperature & 253 to $353 \mathrm{~K}$ \\
Shaft diameter & $8 \mathrm{~mm}$ \\
Body diameter & $50 \mathrm{~mm}$ \\
Output type & Line driver \\
Pulse number per rotation & 1000 \\
Max. operating speed & $4000 \mathrm{rpm}$ \\
\hline
\end{tabular}

In-cylinder pressure was collected with Cussons P4110 combustion analyzer. In-cylinder pressure signals were recorded to the computer with (National Instruments USB6259 model data acquisition card) data from the encoder. The average of 50 consecutive in-cylinder pressure data were used in all operating conditions.

Table 3. Properties of naphtha and n-heptane fuels

\begin{tabular}{lll}
\hline & RON68 & Naphtha \\
\hline Calorific value $(\mathrm{kJ} / \mathrm{kg})$ & 44510 & 43360 \\
RON & 68 & 68 \\
Boiling point $\left({ }^{\circ} \mathrm{C}\right)$ & $98-99$ & 152 \\
Density $\left(\mathrm{kg} / \mathrm{cm} 3\right.$ at $\left.20^{\circ} \mathrm{C}\right)$ & 0.685 & 0.72 \\
Viscosity $(\mathrm{cSt})$ & 0.55 & 0.5 \\
\hline
\end{tabular}

During the operation, the exhaust gases were recorded with the Bosch BEA350 exhaust gas analyzer. The exhaust gas analyzer was measured $\mathrm{HC}$ and $\mathrm{CO}$ emissions. However, lambda was determined by the Brettschneider formula.

50 consecutive pressure data were averaged for incylinder pressure. For thermodynamic analysis, a code was prepared by using MATLAB Simulink program. By using MATLAB Simulink code, ITC, heat release rate, SOC, incylinder pressure, combustion duration and indicated mean effective pressure and MPRR were determined. HRR was determined using the first rule of thermodynamics. The HRR versus to the crank angle was calculated with Eq. 1 .

$\frac{\mathrm{dQ}}{\mathrm{d} \theta}=\frac{\mathrm{n}}{\mathrm{n}-1} \mathrm{P} \frac{\mathrm{dV}}{\mathrm{d} \theta}+\frac{1}{\mathrm{n}-1} \mathrm{~V} \frac{\mathrm{dP}}{\mathrm{d} \theta}+\frac{\mathrm{dQ}_{\text {heat }}}{\mathrm{d} \theta}$

Here, $V$ and $P$ express to cylinder volume and cylinder pressure, respectively. $d Q$ expresses to net heat output. $n$ refers to ratio of specific heat values and $d \theta$ expresses to change of crank angel. $\frac{d Q_{\text {heat }}}{d \theta}$ expresses to heat transfer from cylinder to cooling water system. The work was calculated with Eq. 2.

$$
W_{n e t}=\int P d V
$$

The IMEP is calculated as given in Eq. 3. Here, $V_{\text {stroke }}$ expresses to cylinder swept volume.

$$
I M E P=\frac{W_{\text {net }}}{V_{\text {stroke }}}
$$

\section{Results and Discussion}

In the present study, the effects of naphtha and RON68 on combustion characteristics and performance were experimentally researched. Figure 2 depicts the variations of cylinder pressure and heat release rate with test fuels at 1000 rpm. HCCI combustion was achieved between 1.7 and 2.5 lambda values. Charge composition is one of the most significant factor affecting HCCI combustion phenomena. As seen in Figure 2, low and high temperature oxidation reactions were observed in HCCI combustion. Cylinder pressure and heat release rate decreased with the increased lambda for both test fuels. As expected, lower fuel energy caused to obtain lower heat and in-cylinder pressure. Released heat decreased with leaner mixtures. It was also seen that combustion phasing was advanced with richer mixtures. Auto-ignition reactions can be easily started with the presence of fuel molecules. Furthermore, the most striking 


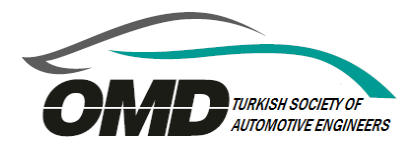

finding from figure 2 is combustion retardation. When RON68 and naphtha were compared in terms of combustion process, combustion was retarded with RON68. RON68 showed more resistance to ignition compared that naphtha. So, combustion phasing is shifted to expansion stroke with RON68. It can be also mentioned that slight knocking tendency was observed with naphtha at $\lambda=1.7$. Richer mixture zones are locally formed at $\lambda=1.7$ in the combustion chamber and rapid heat release is seen due to low-octane number of naphtha.
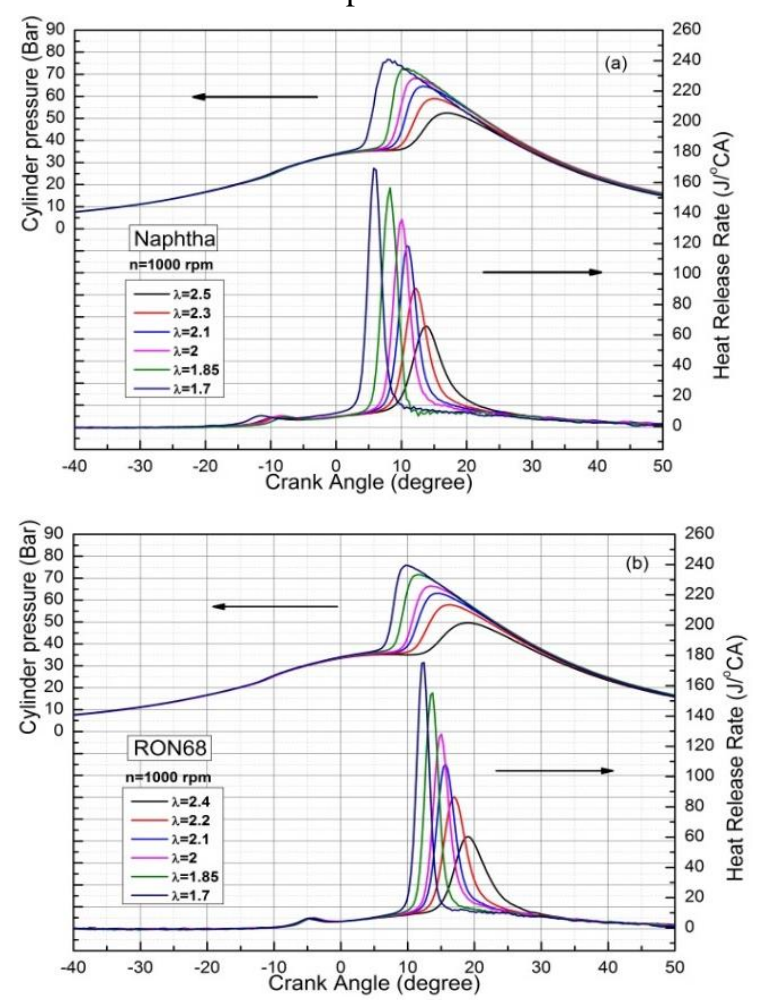

Fig. 2. The effects of Naphtha and RON68 on cylinder pressure and heat release rate

Figure 3 shows the variations of cylinder pressure and heat release rate with test fuels at $\lambda=2$. It is evidently seen that peak cylinder pressure was higher with naphtha compared to RON68. Similarly, heat release rate decreased with RON68. Combustion occurs rapidly with naphtha owing to lower octane number. It can be also attributed to increase combustion rate. On the other hand, lower flashing and auto-ignition temperature of naphtha allow easily occurring oxidation reactions. At this point, it was seen that HCCI combustion process could be controlled with fuel properties and charge composition.

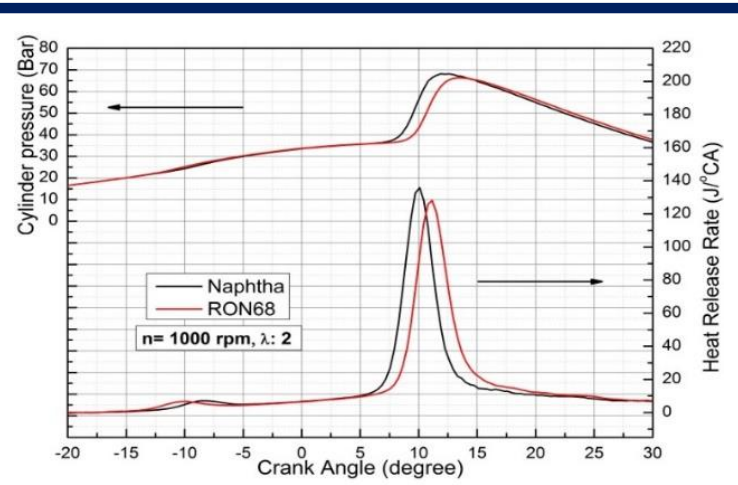

Fig. 3. Comparison of cylinder pressure between Naphtha and RON68

Imep is an important performance indication. Figure 4 presents the imep variations of naphtha and RON68 versus lambda. As lambda increased, imep decreased with test fuels. The highest imep was determined at $\lambda=1.7$ with test fuels. Fuel concentration increases with lower lambda. So, more heat energy is distributed to the combustion chamber. Accordingly, indicated pressure exerted on the piston increases. It was also found that lower imep was obtained with RON68 according to naphtha at specific lambda value. As mentioned in figure 3, the highest cylinder pressure was obtained with naphtha. So, there is good agreement between imep and in-cylinder pressure. It may be said that higher octane number of RON68 made difficult to occur autoignition chemical reactions. Maximum imep was computed as 3.23 and 3.32 bar with RON68 and naphtha respectively at $\lambda=1.7$.

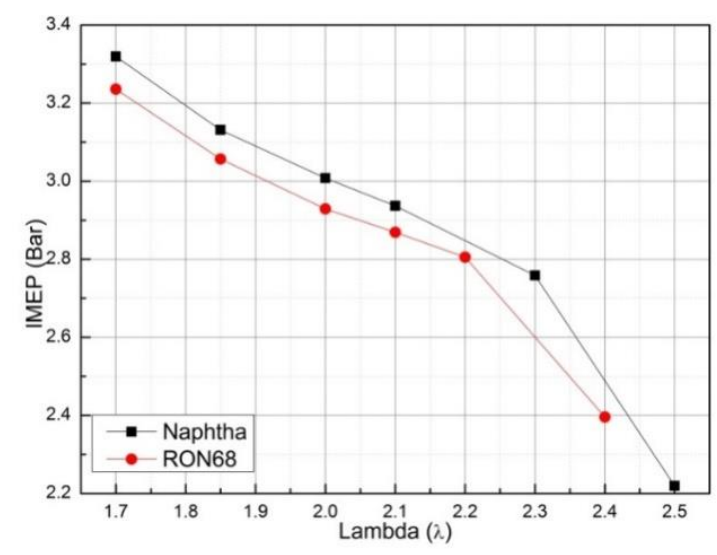

Fig. 4. IMEP variations versus lambda

Development of combustion is mainly dependent on the start of combustion (SOC) in HCCI. The continuation of the combustion is affected by the onset of combustion. Since HCCI combustion has no mechanism like spark plug or igniter, combustion is dominated by thermodynamic situations and composition at the end of compression stroke. Figure 5 illustrates the SOC with test fuels. As lambda in- 


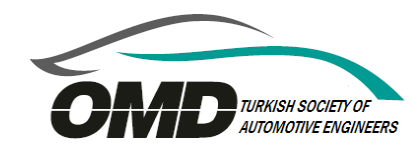

creased, SOC was delayed for both test fuels. However, SOC was advanced with naphtha compared to RON68 at a given lambda. RON68 presented more resistance to start auto-ignition reactions due to higher octane number. It results in retardation of SOC. SOC was determined $5.4^{\circ} \mathrm{CA}$ and $5.76{ }^{\circ} \mathrm{CA}$ ATDC with naphtha and RON68 at $\lambda=2$.RON68 presented delayed combustion in spite of the same octane number. It can be explained that higher boiling point of naphtha showed cooling effect during the vaporization. This phenomena causes to decrease temperature gradient during combustion that prevents to occur auto-ignition reactions easily. Hence, initiation of self-ignition chemical reactions are retarded.

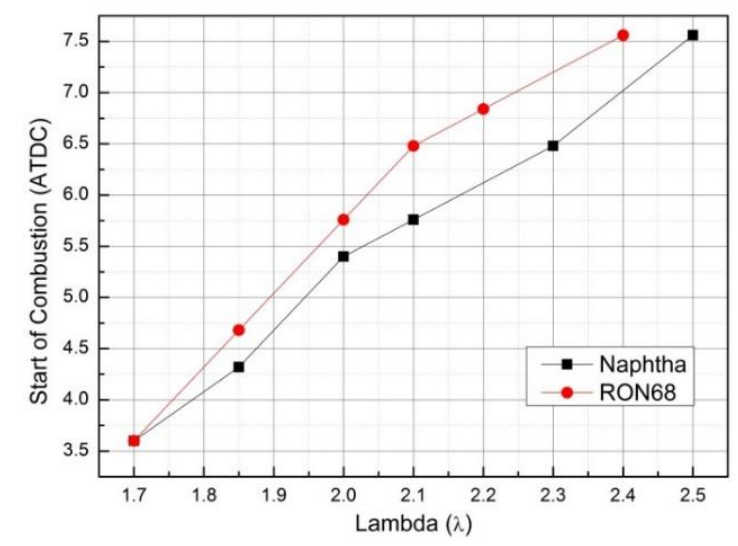

Fig. 5. Start of combustion

Auto-ignition reactions are controlled by chemical kinetics in HCCI combustion. Figure 6 gives the combustion duration $(\mathrm{CD})$ versus lambda. $\mathrm{CD}$ increased with the increase of lambda for both test fuels. In-cylinder gas temperature and obtained cylinder pressure decrease with leaner mixtures due to lower fuel concentration. Combustion process takes longer with the combustion of leaner charge mixture. It can be explained that leaner mixture caused to obtain cooler cylinder wall temperature owing to lower gas temperature in the combustion chamber. It results in prolonged combustion. Auto-ignition reactions could easily occur with naphtha because of lower octane number and combustion process can be completed with a shorter duration. Chemical reactions are rapidly performed due to lower resistance to knocking. As a result, $\mathrm{CD}$ takes shorter time with naphtha. At $\lambda=1.7$ lambda, $\mathrm{CD}$ was determined as 23.04 ${ }^{\circ} \mathrm{CA}$ and $24.12^{\circ} \mathrm{CA}$ with naphtha and RON68 respectively.

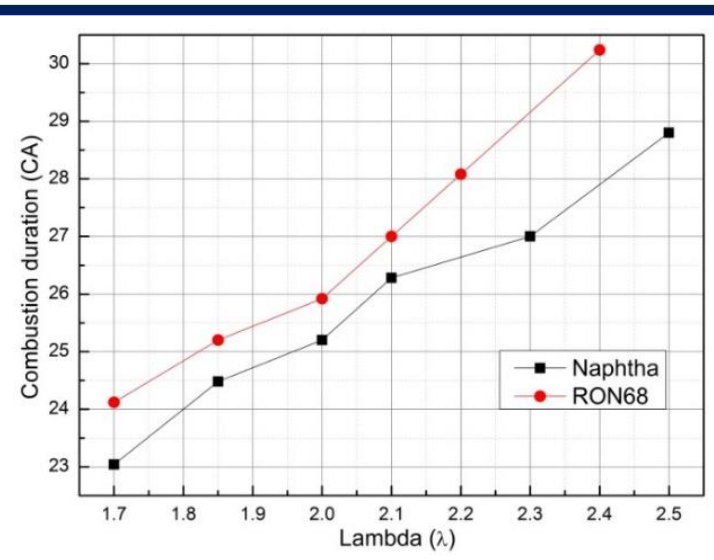

Fig. 6. Combustion duration

Figure 6 shows the CA50 and indicated thermal efficiency (ITE) versus lambda. CA50 is evident to obtain higher ITE. CA50 defines the crank angle position where the half of charge mixture is completed to burn. CA50 should be close to the top dead center (TDC) for reasonable ITE. When Figure 7-a is examined, CA50 is retarded with the increased lambda like CD. Figure 7-b shows the ITE respect to lambda. ITE increased until $\lambda=2$ and then decreased with the increased lambda. Maximum ITE was calculated as $45.42 \%$ and $46.07 \%$ at $\lambda=2$ with RON68 and naphtha respectively. There is good relationship between CA50 and ITE. CA50 should be nearly after top dead center for better ITE. It is corroborated that maximum ITE was obtained at $\lambda=2$ where CA50 was $10.8^{\circ} \mathrm{CA}$ and $11.88^{\circ} \mathrm{CA}$ ATDC with naphtha and RON68 respectively. CA50 is far away from TDC fact that net work decreases. Hence, ITE decreases. At leaner charge mixtures, released heat is decreased due to lower fuel concentration resulting in lower ITE. Lower net work is obtained with leaner mixtures. As a result, ITE decreased. 

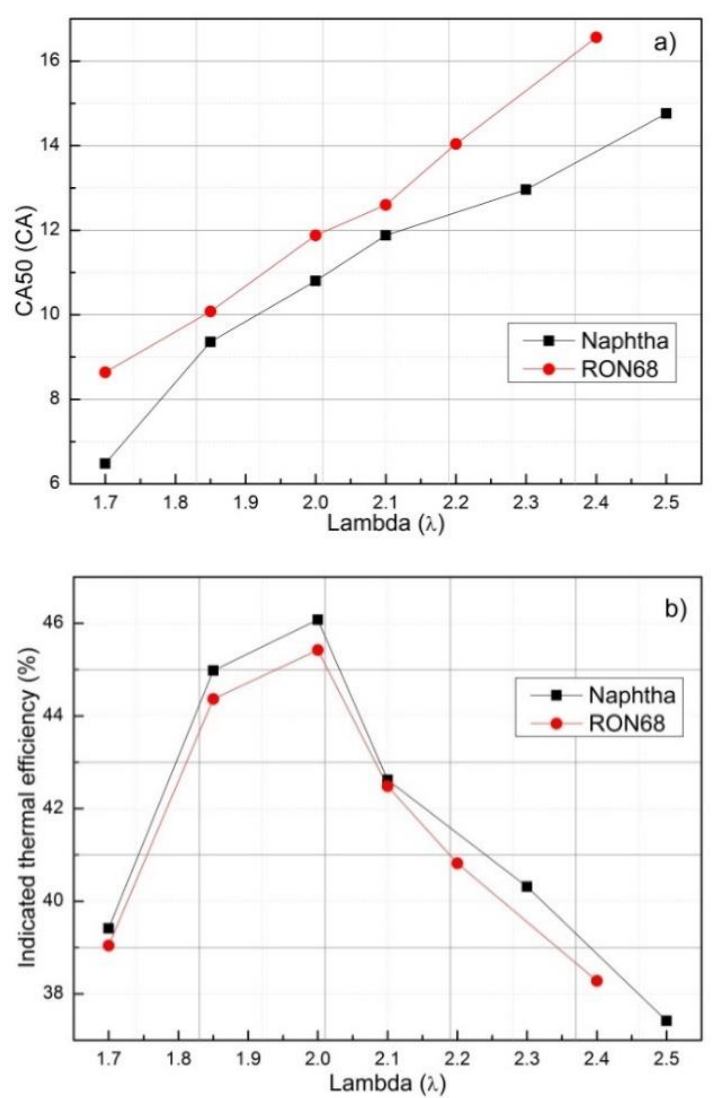

Fig. 7. CA50 and indicated thermal efficiency versus lambda

Maximum pressure rise rate can be defined as the operating limit in view of stable operation. MPRR also gives information about knocking. Figure 8 refers to MPRR respect to lambda. Evidently, MPRR decreased with the increase of lambda. It can be mentioned that combustion rate and speed increase with richer mixtures. This phenomenon caused to rapid and sudden heat release. Moreover, knocking that damages engine parts is seen. At this point, in-cylinder pressure increased too much applied to the piston according to crank angle. MPRR was computed at $\lambda=1.7$ as 16.02 bar $/{ }^{\circ} \mathrm{CA}$ and $16.46 \mathrm{bar} /{ }^{\circ} \mathrm{CA}$ with RON68 and naphtha respectively. Decrease of the fuel concentration in the combustion chamber causes to obtain lower heat and cylinder pressure. Naphtha showed more flammability than RON68 due to lower octane number. It resulted in improvement of auto-ignition reactions. It can be said that more stable HCCI combustion was observed with leaner mixtures for both fuels.

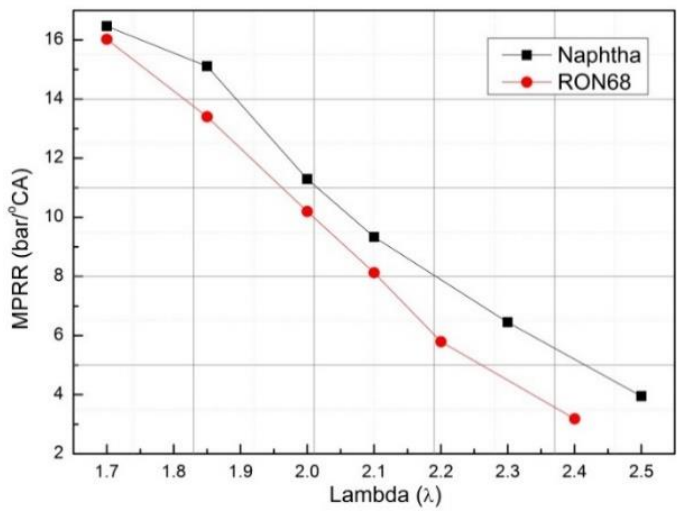

Fig. 8. The variations of MPRR

$\mathrm{CO}$ and $\mathrm{HC}$ are two important sources of emissions in HCCI engines, because HCCI combustion provides to combust leaner mixtures with higher thermal efficiency. Figure 9 shows the changes of $\mathrm{HC}$ and $\mathrm{CO}$ versus lambda. As flame goes out near the cooler cylinder wall, $\mathrm{HC}$ is formed especially with leaner mixtures. HC increased with the increased lambda as seen in Figure 9-a. In-cylinder gas temperature gradient reduces towards to combustion chamber due to combustion of poorer mixture. This evident prevents to complete combustion and unburned $\mathrm{HC}$ increases. It was also found that $\mathrm{HC}$ reduced with naphtha compared to RON68 at a given lambda. HC reduced by $20.6 \%$ with naphtha compared to RON68 at $\lambda=2$. Rapid combustion process of naphtha enhances to occur oxidation reactions even at cavities of the combustion chamber. Hence HC reduced. Similar changes are seen on $\mathrm{CO}$ emissions as given in Figure 9-b. Unless complete combustion is occurred, $\mathrm{CO}$ is produced due to insufficient oxygen and reaction temperature during combustion. $\mathrm{CO}$ increased with the increase of lambda for both fuels, because lower heat energy is released to the combustion chamber. This effect prevents to complete combustion. So, $\mathrm{CO}$ is formed. Minimum $\mathrm{CO}$ was measured at $\lambda=1.7$ as $0.055 \%$ and $0.072 \%$ with naphtha and RON68 respectively. Oxidation reactions improve with the combustion of richer mixtures and $\mathrm{CO}$ formation disappears. On the contrary, $\mathrm{CO} 2$ formation is seen with high enough in-cylinder gas temperature during HCCI combustion. 


\section{References}
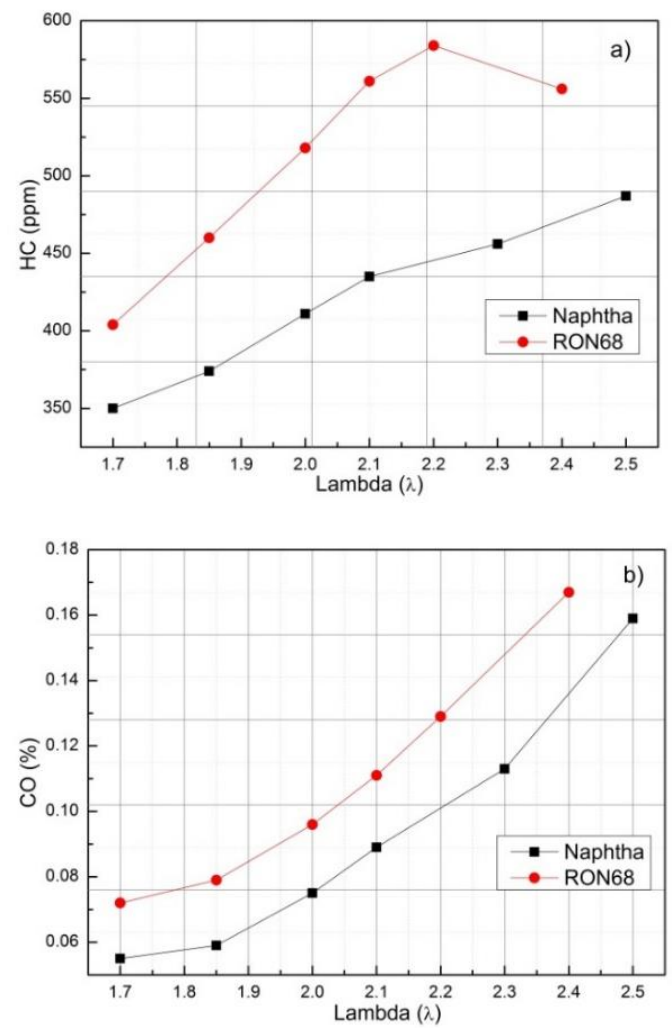

Fig. 9. $\mathrm{HC}$ and $\mathrm{CO}$ emissions

\section{Conclusions}

In this study, RON68 and Naphtha fuels with different physical and chemical properties were tested on a single cylinder port-injection water cooled HCCI engine and their effects on combustion, performance and exhaust emissions were investigated. The effects of the test fuels on incylinder pressure, heat release rate, SOC, combustion duration, IMEP, ITE, $\mathrm{CO}$ and $\mathrm{HC}$ emissions were also examined.

It was determined that, thanks to the low flash point and the self-ignition temperature, oxidation reactions that occur easily with naphtha higher in-cylinder pressure and heat distribution rates were obtained achieved compared to RON68.

In addition, with the use of naphtha and RON68, the lowest $\mathrm{CO}$ emission values were observed as $0.055 \%$ and $0.072 \%$ at $\lambda=1.7$, respectively. Likewise, the lowest $\mathrm{HC}$ emissions are at $\lambda=1.7$ for both fuels.

As a result of the current research, it has been observed that naphtha can be used effectively in HCCI engines. In addition, it can be examined whether the HCCI working range can be extended by blending with naphtha n-heptane or other alternative fuels.
[1] Maurya, R. K. (2017). Characteristics and control of low temperature combustion engines: employing gasoline, ethanol and methanol, Cham, Switzerland. Springer International Publishing AG, 2-10.

[2] International Energy Agency (2010). World energy outlook. International Energy Agency, France. isbn 978-92-64-086241. www.iea.org.

[3] U.S. Energy Information Administration (2016). International energy outlook.

[4] T. S. Uyar. (2001). What is the energy problem? Is it an alternative energy solution? NEU-CEE 2001 Electrical, Electronic and Computer Engineering Symposium, 23-26, Lefkoşa TRNC.

[5] Pan, S., Liu, X., Cai, K., Li, X., Han, W., \& Li, B. (2020). Experimental study on combustion and emission characteristics of iso-butanol/diesel and gasoline/diesel RCCI in a heavy-duty engine under low loads. Fuel, 261, 116434.

[6] İpci, D., Y1lmaz, E., Aksoy, F., Uyumaz, A., Polat, S., \& Solmaz, H. (2015). The Effects of iso-propanol and n-heptane Fuel Blends on HCCI Combustion Characteristics and Engine Performance. Electronic Journal of Machine Technologies, 12(1), 49-56.

[7] Bastawissi, H. A. E., Elkelawy, M., Panchal, H., \& Sadasivuni, K. K. (2019). Optimization of the multi-carburant dose as an energy source for the application of the HCCI engine. Fuel, 253, 15-24.

[8] Solmaz, H., Kocakulak, T. (2018). Modelling of a Serial Hybrid Electric Vehicle with Spark Ignition Engine. In Proceedings on International Conference on Technology and Science, December.

[9] Kocakulak, T., Solmaz, H. (2019). Modeling of an electric vehicle and controlling the regenerative brake system with fuzzy logic method. International Symposium on Automotive Science and Technology, September.

[10]Kocakulak, T., Konukseven, E.İ., Çokgünlü, S.A. (2019). Modeling of hydro pneumatic suspension system to be used on $6 \times 6$ tactical wheeled military land platform and investigation of the effect of system elements on damping. International Symposium on Automotive Science and Technology, September.

[11]Kiyaklı, A. O. \& Solmaz, H. (2018). Modeling of an electric vehicle with MATLAB/Simulink. International Journal of Automotive Science and Technology, 2(4), 9-15.

[12]Uyumaz, A. (2018). Combustion, performance and emission characteristics of a DI diesel engine fueled with mustard oil biodiesel fuel blends at different engine loads. Fuel, 212, 256267.

[13]Gómez, A., García-Contreras, R., Soriano, J. A., \& Mata, C. (2020). Comparative study of the opacity tendency of alternative diesel fuels blended with gasoline. Fuel, 264, 116860.

[14]Sadeq, A. M., Bassiony, M. A., Elbashir, A. M., Ahmed, S. F.,Khraisheh, M. (2019). Combustion and emissions of a diesel engine utilizing novel intake manifold designs and run- 
ning on alternative fuels. Fuel, 255, 115769.

[15]Ardebili, S. M. S., \& Khademalrasoul, A. (2018). An analysis of liquid-biofuel production potential from agricultural residues and animal fat (case study: Khuzestan Province). Journal of cleaner production, 204, 819-831.

[16]Setiyo, M., \& Waluyo, B. (2019). Mixer with secondary venturi: an invention for the first-generation LPG kits. International Journal of Automotive Science and Technology, 3(1), 21-26.

[17]Londhe, H., Luo, G., Park, S., Kelley, S. S., \& Fang, T. (2019). Testing of anisole and methyl acetate as additives to diesel and biodiesel fuels in a compression ignition engine. Fuel, 246, 79-92.

[18]Keskin, A., Yaşar, A., Yıldızhan, Ş., Uludamar, E., Emen, F. M., \& Külcü, N. (2018). Evaluation of diesel fuel-biodiesel blends with palladium and acetylferrocene-based additives in a diesel engine. Fuel, 216, 349-355.

[19]Halis, S., Nacak, Ç., Solmaz, H., Yilmaz, E., \& Yücesu, H. S. (2018). Investigation of the effects of octane number on combustion characteristics and engine performance in a HCCI engine. Journal of Thermal Science \& Technology, 38(2).

[20]Polat, S., Yücesu, H. S., Kannan, K., Uyumaz, A., Solmaz, H., \&Shahbakhti, M. (2017). Experimental comparison of different injection timings in an HCCI engine fueled with nheptane. International Journal of Automotive Science and Technology, 1(1), 1-6.

[21]Rather, M. A., \&Wani, M. M. (2018). A numerical study on the effects of exhaust gas recirculation temperature on controlling combustion and emissions of a diesel engine running on HCCI combustion mode. International Journal of Automotive Science and Technology, 2(3), 17-27.

[22]Uyumaz, A., Aydoğan, B., Calam, A., Aksoy, F., \& Y1lmaz, E. (2020). The effects of di isopropyl ether on combustion, performance, emissions and operating range in a HCCI engine. Fuel, 265, 116919.

[23]Calam, A., Aydoğan, B., \& Halis, S. (2020). The comparison of combustion, engine performance and emission characteristics of ethanol, methanol, fusel oil, butanol, isopropanol and naphtha with n-heptane blends on HCCI engine. Fuel, 266, 117071.

[24]Waqas, M. U., Hoth, A., Kolodziej, C. P., Rockstroh, T., Gonzalez, J. P., \& Johansson, B. (2019). Detection of low Temperature heat release (LTHR) in the standard Cooperative Fuel Research (CFR) engine in both SI and HCCI combustion modes. Fuel, 256, 115745.

[25]Gharehghani, A. (2019). Load limits of an HCCI engine fueled with natural gas, ethanol, and methanol. Fuel, 239, 1001-1014.

[26]Noguchi M, Tanaka Y, Tanaka T, Takeuchi Y, (1979). A Study on gasoline engine combustion by observation of intermediate reactive products during combustion. SAE Technical Paper. https://doi.org/10.4271/790840.

[27]Onishi S, Jo SH, Shoda K. (1979). Active ThermoAtmosphere Combustion (ATAC) - a new combustion process for internal combustion engines. SAE Trans:1851-60.
[28]Shi, H., Tang, Q., An, Y., Raman, V., Sim, J., Chang, J., Johansson, B. (2020). Study of spray/wall interaction in transition zones from HCCI via PPC to $\mathrm{CI}$ combustion modes. Fuel, 268, 117341.

[29]Calam, A., Solmaz, H., Yılmaz, E., \& İçingür, Y. (2019). Investigation of effect of compression ratio on combustion and exhaust emissions in A HCCI engine. Energy, 168, 12081216.

[30]Polat, S., Solmaz, H., Calam, A., \& Y1lmaz, E. Estimation of the COVIMEP Variation in a HCCI Engine. Journal of Polytechnic. DOI: 10.2339/politeknik.567865

[31]Polat, S., Solmaz, H., Yılmaz, E., Calam, A., Uyumaz, A., \& Yücesu, H. S. (2019). Mapping of an HCCI engine using negative valve overlap strategy. Energy Sources, Part A: Recovery, Utilization, and Environmental Effects, 1-15.

[32]Shim, E., Park, H., \& Bae, C. (2020). Comparisons of advanced combustion technologies (HCCI, PCCI, and dual-fuel PCCI) on engine performance and emission characteristics in a heavy-duty diesel engine. Fuel, 262, 116436.

[33]Calam, A., \& İçingür, Y. (2019). The effects of air fuel ratio and octane number on HCCI combustion and engine performance characteristics. Journal of Polytechnic, 22(3), 607-618.

[34]Bastawissi, H. A. E., Elkelawy, M., Panchal, H., \& Sadasivuni, K. K. (2019). Optimization of the multi-carburant dose as an energy source for the application of the HCCI engine. Fuel, 253, 15-24.

[35]Putrasari, Y., Jamsran, N., \& Lim, O. (2017). An investigation on the DME HCCI autoignition under EGR and boosted operation. Fuel, 200, 447-457.

[36]Kozlov, V. E., Titova, N. S., \& Chechet, I. V. (2018). Modeling study of hydrogen or syngas addition on combustion and emission characteristics of HCCI engine operating on isooctane. Fuel, 221, 61-71.

[37]Poorghasemi, K., Saray, R. K., Bahlouli, K., \& Zehni, A. (2016). 3D CFD simulation of a natural gas fueled HCCI engine with employing a reduced mechanism. Fuel, 182, 816830.

[38]Lacey, J., Kameshwaran, K., Filipi, Z., Cannella, W., \& Fuentes-Afflick, P. (2014). Influence of ethanol addition in refinery stream fuels and the HCCI combustion. Fuel, 126, 122-133.

[39]Speight, J. G. (2007). The Chemistry and Technology of Petroleum Fourth Edition Preface.

[40]Wang, B., Wang, Z., Shuai, S., Yang, H., \& Wang, J. (2014). Combustion and emission characteristics of Multiple Premixed Compression Ignition (MPCI) fuelled with naphtha and gasoline in wide load range. Energy conversion and management, 88, 79-87.

[41]Vallinayagam, R., An, Y., Vedharaj, S., Sim, J., Chang, J., \& Johansson, B. (2018). Naphtha vs. dieseline-The effect of fuel properties on combustion homogeneity in transition from CI combustion towards HCCI. Fuel, 224, 451-460. 